\title{
Exploration of implementing the opening extracurricular innovation experiment
}

$$
\text { Le Gao }{ }^{1, a} \text {,Changying Liu }{ }^{2, b}, \text { Zhanyang An }{ }^{3, c} \text {,Tianhao Wang }{ }^{4, d}
$$

${ }^{1,2,3}$ College of Instrumentation\& Electrical Engineering, Jilin University, Changchun, Jilin, China

${ }^{4}$ State Key Laboratory of automobile simulation and control, Jilin University, Changchun, Jilin, China

agaole@jlu.edu.cn,

d liuchangy@jlu.edu.cn,,anzhanyang2010@126.com, dwangtianhao2006@126.com

\begin{abstract}
Keywords: undergraduate; inovative talents; science and technology innovation ability; innovation
\end{abstract} consciousness

\begin{abstract}
Cultivating innovative talents is the key of the current higher education goals. The opening extracurricular innovation experiment is to develop a new era with science and technology innovation ability and innovation consciousness of undergraduates. Combined with the college in the implementation of the opening extracurricular innovation experimental project idea, process and finally harvest the fruits of students, really see the validity of the opening extracurricular innovation experimental project and achieved initial results.
\end{abstract}

\section{Introduction}

National college students' innovative experiment plan is during the period of "the Eleventh Five-Year Plan" of the ministry of education to promote the innovative talents training work is an important reform measures, is part of the "quality project", is a state-level directly to college students, pay attention to the autonomy, exploration, process, collaboration and discipline of innovation training project ${ }^{[1]}$. The implementation of the plan, aimed at cultivating students engaged in scientific research and interest in explorating the unknown, to inspire students' thinking and innovative consciousness, exercise the ability of college students' thinking, problem solving, and cultivate their quality to engaged in scientific research and invention ${ }^{[2]}$.

\section{The purpose of the implementation of open extracurricular innovation experiment}

The main purpose of opening the open extracurricular innovation experiment lies in the fact that promote the colleges and universities to explore a new mode of innovative talents cultivation, promote the colleges and universities to explore and establish teaching pattern as the core of problems and issues, advote undergraduate talents cultivation and research teaching reform as the main body of students, mobilize students' learning initiative, enthusiasm and creativity, stimulate students' creative thinking and innovation consciousness, so that students practice in research projects to develop awareness of the problem was found, the master way of thinking, problem solving, improve their innovation and practical ability, leading universities reform innovative training model ${ }^{[3]}$.

\subsection{To cultivate the innovative ability of undergraduates and innovation consciousness}

Innovative talents need to have innovation ability and innovation consciousness, and opening extracurricular innovation experiment is the best way to cultivate the innovative ability of undergraduates and innovation consciousness.In the traditional teaching, textbook knowledge are teached students by teachers in class teaching, the main task of students is understanding and memory; In class experiment, students only need to according to the experimental instruction given by the experimental steps, observe or verify the experimental results one by one. In opening extracurricular innovation experiment, first students choose their interested topic, then consult their own courses content according to the experiment data, design the experimental steps, complete the experiment project. In the whole process, It mobilize the enthusiasm and subjective initiative of the 
students, open the innovation consciousness of students, cultivate the innovation ability of students ${ }^{[3]}$.

\subsection{To set up the new teaching mode and teaching idea as the main body of students.}

In traditional teaching mode, with teachers as the main body, the teacher teaching and student learning, students are just passively grantor. Many students blindly learn by rote, have a superficial of learned knowledge which cannot be applied to practice, so that it appears a high score low-energy students. Such students lack practical ability, also do not have the consciousness of the independent thinking, lack of innovation and initiative. To change this situation, it needs to break the old model, set up new teaching mode as the main body of students. The implementation of the open extracurricular innovation experiment, is the best way to change the old teaching mode, create new teaching idea. Through the process of students participate in extracurricular innovation experiments in the topic selection, open design, self-study, research, reflection, motivate their self-study, trigger their interest in learning, training their scientific research ability, cultivate their innovation consciousness, guide their innovation ability, then quickly and stablly set up the new teaching idea of"students initiative, teachers assist", to cultivate more creative talent for the country.

\section{The exploration and practice of opening extracurricular innovation experiment}

\subsection{To create a good atmosphere}

In order to successfully carry out open extracurricular innovation experiments, It formulate a variety of measures to create a good innovation atmosphere for students, establish good cultural environment to mobilize students' participation. Most of the students grew up from childhood for traditional education mode lack the ability of independent thinking and the spirit of innovation. To better arouse the enthusiasm of the students to participate in, it used various methods to promote the importance of extracurricular innovation experiment to all students. Today's society is the information society, the network as a means of communication, is a very good propaganda way to the students. Setting up the column innovation on the college website, conprehensivly introduce the opening extracurricular innovation experiment, and forming QQ group of undergraduate students, in the QQ group post a link on the relating information of the opening extracurricular innovation experiment, prompting students to log in college website for understanding the content and related information of open extracurricular innovation experiment. A variety of ways, such as organizing counselors meeting termly, seniors with juniors in small groups to discuss academic, professional teachers' lectures, propagandizing by printing college publications, publicize opening extracurricular innovation experiment in all directions. In addition, through application from division of laboratory and equipment of school, transfer by the teachers' funding for scientific research and cooperation with enterprises, for the smooth implementation of the open extracurricular innovation experimental project to raise funds, to ensure that the project runs muchly and efficiently.

\subsection{To establish a sound guidance mechanism}

Opening extracurricular innovation experiment based on subject basic course, professional backbone courses and directed characteristic course formed a comprehensive, design and innovative experimental project by the combination and refining. Put forward by the institute of experimental center to perform and supervise the whole project implementation process. Experiment center designate an experiment teacher to an opening extracurricular innovation experimental project director, the student instructor is responsible for organizing a guidance of students, the teacher in charge to assist students selected topic, professional teachers is the guidance of teachers of the course corresponds to the experiment project, to formulate related extracurricular innovation experimental content of the project, examine and approve the design scheme of students answer student design question, acceptance of the result of the experiment, experiment result is given; The experiment center is responsible for the implementation of experiment site; Experimental teachers is responsible for the open laboratory and provide experimental instruments and equipment; Project director is responsible for the fellow teachers to write the content of the project summary of the book, collect students choose good experiment table, the statistical number and guidance teachers, 
experimental work completed, and make students obtain the openness of extracurricular innovation experiment results fill in the project archive BaoShen table was built. By establishing the guidance of regulators, promoted the opening extracurricular innovation experiment in the right direction to better and faster development.

\subsection{To found a standardized operation process}

Guidance teachers write the openness of extracurricular innovation experiment name, requirements, hours and credit of related courses. Project leader is responsible for the collection of projects together into "The opening extracurricular innovation experiment table", makes "The application for opening extracurricular innovation experiment project", published on the school website for students to download. Students choose their favorite opening extracurricular innovation experimental subject according to the content of the project and requirements in "The opening extracurricular innovation experiment table" after download "The application for opening extracurricular innovation experiment project", design the experiment scheme and steps themseleves in light of the given project content and requirements. Then Guidance teachers check their design scheme whether through the approval. List for approval by the project leader announced to the Internet, the students did not pass until the need to re-design given by the instructor. Students' applications were passed who need to complete the experiment independently in the related laboratory, submit the experimental work, write the experimental report.After completing guidance teachers check experimental results and works, produce the experimental result. Project director registered students openness of extracurricular innovation experiment result, archiving copies. Project leader registered students' result of opening extracurricular innovation experiment, archiving and building volumes. By formulating that standard operating procedures ensure the effective operation of the opening extracurricular innovation experiments.

\subsection{To form a complete set of incentive policy}

Because of the opening extracurricular innovation experiments involving many factors in the implementation process, establishing a sound incentive system is crucial. Referring to the development of the school given by the relevant provisions of "the opening extracurricular innovation experimental project" computing approach, reasonably calculate the work involved, give the special prize rewards. For students complete opening extracurricular innovative experiment independently, give four different credit award including 0.5,1,1.5,2, among them eight hours corresponds to 0.5 credits, sixteen hours corresponds to 2 credit, twenty-four hours corresponds to 1.5 credits, thirty-six hours corresponds to 2 credits. This policy encourages participants to dedicate themselves to the opening extracurricular innovative experiments, but also stimulates the students' enthusiasm to participate in the opening extracurricular innovative experiments.

\section{Conclusion}

Since 2010 for 2009 undergraduates start to perform the opening extracurricular innovative experimental project which executed for three years, our college students published thirty-five journal articles through the opening extracurricular innovative experiment, which was retrieved EI is one paper, core journals is ten papers, obtained thirteen patents for utility model. Works of the opening extracurricular innovative experiment by students won twenty-one national science and technology competition prize, fifty-nine provincial science and technology competition prize. A significant increase in students winning projects, since the implementation of the opening extracurricular innovative experimental project,which achieved remarkable success for the development of students' creative thinking and innovation consciousness, and cultivating more innovative research talent for our country.

\section{References}

[1] Yang Chen, Dayuan Yan, Daofu Ming: Journal of Beijing Institute of Technology(Social Sciences Edition), Vol.11(2009)No.2,p93. 
[2] Wenbin Sun: Reserch and Exploration in Laboratory, Vol.25(2006)No.2,p148.

[3]Hong Zhen , Maolan Li: Journal of East China Institute of Technology, Vol.28(2009)No.3,p294.

[4] Hebing Zhou, Xiaobo Huang, Wenhuai Shen: Reserch and Exploration in Laboratory, Vol.28(2009)No.8,p4. 